Revista Calundu - vol.3, n.1, jan-jun 2019

\title{
O QUE O JULGAMENTO DO STF SOBRE O ABATE RELIGIOSO TEM A NOS DIZER?
}

\author{
Andréa Letícia Carvalho Guimarães ${ }^{1}$ \\ Calundu - Grupo de Estudos sobre Religiões Afro-Brasileiras ${ }^{2}$
}

DOI: 10.26512/revistacalundu.v3i1.25244

É importante que se faça uma reflexão sobre o julgamento do abate religioso praticado pelas religiões afro-brasileiras no Supremo Tribunal Federal (STF).

Primeiramente, questionam-se as razões pelas quais apenas o abate religioso, prática alimentar ancestral das tradições afro-brasileiras (animais são abatidos para consumo da carne), estar sendo avaliado, sendo que inúmeras outras religiões também praticam o sacrifício de animais em suas ritualísticas. Não seria o próprio julgamento a representação de como as religiões afro-brasileiras tem sido perseguidas, discriminadas e violentadas?

Segundo, a existência de um julgamento sobre essas práticas denuncia a continuidade da repressão histórica vivenciada pelos cultos afro-brasileiros, alimentando a ideia de que tudo aquilo que representa essas religiões precisa ser extinto/proibido. Pois, consideram, discriminatoriamente, tratar-se de práticas "bárbaras" alheias à modernidade, representando o atraso civilizatório e estando contra o progresso da nação.

Terceiro, o julgamento confirma o grande engano de que as práticas tradicionais afro-brasileiras para serem legítimas precisam de "autorização" para serem vivenciadas. Estão novamente sob o julgo das "autoridades" (brancas, cristãs, masculinas), como ocorria na década de 40, em que precisavam de registro nas Delegacias de Bons Costumes para que pudessem ser praticadas.

Esses são alguns dos inúmeros pontos que podemos extrair do que significa o julgamento do abate religioso, ou seja, representa a confirmação de que vivemos em uma sociedade racista, e que a "galinha preta da macumba" incomoda muita gente.

1 Mestra em Direito, Estado e Constituição pela Universidade de Brasília. Advogada. Professora de Direito Público. Integrante do Calundu - grupo de estudos sobre as religiões afro-brasileiras (UnB). Integrante do Centro Cultural Orè. andreacarvalhoguimaraes@gmail.com

${ }^{2}$ Texto de nota política publicada também na página do Calundu. Fazem parte do grupo: Adélia Regina da Silva Mathias, Aisha Angele Leandro Diéne, Ariadne Moreira Basílio, Clara Jane Costa Adad, Danielle de Cássia Afonso Ramos, Francisco Phelipe Cunha Paz, Gerlaine Torres Martini, Guilherme Dantas Nogueira, Hans Carrillo Guach, Iyaromi Feitosa Ahualli, Luís Augusto Ferreira Saraiva, Nathalia Vince Esgalha Fernandes, Tania Mara Campos de Almeida. 
Revista Calundu - vol.3, n.1, jan-jun 2019

Contudo, apesar de absurdo esse julgamento, a decisão proferida pelo STF tem aspectos positivos, que são importantes para o fortalecimento da luta dos povos de terreiro e reconhecimento das violências cotidianas, que já tem sido denunciada por vários dados. Por exemplo, entre 2011 e 2017, o Disque 100 registrou 2356 denúncias de discriminação religiosa, sendo que 508 casos se referem a pessoas que se declaram pertencentes às religiões de matriz africana - uma média $20 \%$ do total de denúncias registradas no período (MDH, 2019).

Os estados do Rio de Janeiro e de São Paulo possuem o maior número de registros de denúncias, sendo 111 casos $(19,88 \%)$ e 99 casos $(19,49 \%)$ respectivamente. A região Sudeste registrou, no período de 2011 e 2017, um quantitativo de 252 casos de vítimas de intolerância pertencentes a religiões de matriz africana, seguido da região Norte (136), Sul (51), Nordeste (31) e Centro-Oeste (26) (MDH, 2019).

Essa situação também fica evidenciada no Relatório de Intolerância e Violência Religiosa no Brasil (2016), pois ele aponta que, nas ouvidorias, a maioria das vítimas também pertence a religiões de matriz africana (MDH, 2016). Nos dados relativos ao Disque 100 da Secretaria Especial de Direitos Humanos (SDH), em 2015, as denúncias de discriminação religiosa computaram um aumento de $69,13 \%$ em relação ao ano anterior. Candomblecistas e umbandistas são os mais recorrentes alvos dos ataques também segundo o Disque 100 (cf. MDH, 2016).

Ao se traçar o perfil das vítimas que aparecem nas denúncias recebidas nas ouvidorias, $47 \%$ delas se autodeclaram pardas e $17 \%$ pretas. Somadas, têm-se um percentual de $64 \%$ de pretos e pardos contra $34 \%$ que se autodeclaram brancas e $2 \%$ indígenas. O número representa $35,2 \%$ do total de vítimas e $60,8 \%$ do total de vítimas que declararam a cor de pele, evidenciando que a população negra é mais vitimada (cf. MDH, 2016).

Vale ressaltar que os dados computam apenas os casos denunciados e, pelo perfil dos praticantes da religião, incluídos nas camadas mais baixas da população, e por seu histórico com a institucionalidade, a conclusão é de que o número de ocorrências diárias é muito maior. Quando denunciados, a maior parte dos casos não é punida. Os próprios gestores, em entrevista, explicam e associam a cifra ao racismo e à história da sociedade brasileira de negação dessa tradição religiosa.

Em uma de suas conclusões, o relatório aponta que a maioria das vítimas é de fiéis das religiões de matriz africana, exceto nos dados das fontes judiciais, onde a maioria das vítimas é evangélica. Isso evidencia a falta de acesso ao judiciário pelos 
Revista Calundu - vol.3, n.1, jan-jun 2019

religiosos de matriz africana, pois, apesar de nas outras fontes de pesquisas e estudos as religiões de matrizes africanas representarem maioria das vítimas, quando vamos estudar os processos judiciais, elas não chegam a $10 \%$ das vítimas que acessaram o judiciário, ainda que as razões para o gargalo devam ser investigadas (MDH, 2016).

Além dos dados, que já denunciam as violências vivenciadas pelas religiões de matriz africana, ontem, o STF, guardião da Constituição Federal, reconheceu a existência do racismo religioso na sociedade brasileira. Como no voto da Ministra Carmem Lúcia

também reconheço que a inclusão da referência aos cultos e liturgias das religiões de matriz africana se dá exatamente pela circunstância de haver preconceito na sociedade, contra tudo que se tem na Constituição e nas leis no Brasil. Mas é um pouco mais do que preconceito aos cultos, é em relação a uma origem tragicamente não acabada daqueles que em grande parte são descendentes de linhagens africanas (BRASIL, 2019).

Esse pronunciamento é um precedente importante para o reconhecimento de que a discriminação vivenciada pelas religiões afro-brasileiras não se resume apenas à intolerância religiosa, mas, também, baseia-se pela origem dessas religiões, ou seja, da origem africana das suas práticas, o que é conceituado teoricamente como racismo religioso.

E, por que isso é importante? Porque quando reduzimos à intolerância religiosa, a discussão é reduzida apenas ao aspecto religioso. Assim, não se consegue fazer a interseccionalidade necessária com o problema, pois a discriminação não tem um viés apenas religioso, envolve também raça, classe social e gênero, precisando ser avaliada na raiz.

Assim, a decisão do abate religioso reconhece o que as notórias religiosas e ativistas do Movimento Afrorreligioso, hoje falecidas, mãe Beata de Iemanjá e makota Valdina categorizavam como racismo religioso, ou seja, o que se ataca é precisamente a origem negro-africana destas religiões (FLOR DO NASCIMENTO, 2017). Há uma estratégia racista em demonizar as religiões de matrizes africanas, fazendo com que elas apareçam como o grande inimigo a ser combatido, não apenas com o proselitismo nas palavras, mas também com ataques aos templos e, mesmo, à integridade física e à vida dos participantes destas religiões. Portanto, o que visualizamos sob a forma da intolerância religiosa nada mais é que uma faceta do pensamento e prática racistas. 
Revista Calundu - vol.3, n.1, jan-jun 2019

A cor de grande parte dos membros dos povos de terreiro e as suas raízes africanas são parte da motivação do preconceito e das ações discriminatórias direcionadas aos mesmos. A argumentação é de que esse preconceito estaria ligado à formação colonial, à divisão e valoração racial negativa, influenciando na compreensão desta religião.

Ariadne Basílio de Oliveira (2017) fala sobre os modos como o racismo foi construído histórica e socialmente a partir da modernidade. Segundo ela,

tais modos passam pela colonialidade do poder, ou seja, pelas marcas deixadas pelos colonizadores e que são perpetuadas até a atualidade. A lógica da colonialidade do poder faz com que as populações não europeias sejam consideradas como inferiores e excluídas da construção de instituições e mecanismos de poder sociais. Sendo assim, tudo que é associado ao não europeu é inferiorizado e tende a ser substituído pelo padrão civilizacional europeu ocidental. Nesse contexto, está a exclusão das religiões afro-brasileiras que possuem um modo de vida diferenciado da modernidade eurocentrada ocidental, que podem ser expressas através dos diferentes modos de vivenciar o gênero, a construção familiar, as relações sociais, a produção e transmissão de conhecimento e suas relações econômicas. (OLIVEIRA, 2017)

Além do reconhecimento do racismo religioso, reconhece-se nos votos que o direito fundamental à igualdade só pode ser lido na sua diferença. Como no voto do Ministro Alexandre de Moraes:

se a interpretação da lei não fosse preconceituosa, não haveria necessidade de exceção (...) aqueles que sustentaram a necessidade de vedação à crueldade e maus tratos aos animais como se isso fizesse parte da sacralização erraram de longe, bastava ter ido uma vez a um terreiro de candomblé e assistido ao ritual". E no voto do Ministro Roberto Barroso: "É constitucional a Lei de Proteção Animal que, a fim de resguardar a liberdade religiosa, permite o sacrifício ritual de animais em cultos religiões de matriz africana (BRASIL, 2019).

Ou seja, os votos possibilitam um novo caminho interpretativo para a compreensão constitucional das práticas ancestrais realizadas pelas religiões de matriz africana.

A interpretação da Constituição precisa ser realizada de modo que o direito à liberdade religiosa seja vivenciado por todas as religiões. E, isso só é possível, quando se compreende que nem todas as religiões tem acesso igualitário a direitos. Por isso, o princípio da igualdade como direito à diferença deve ser a base interpretativa dos 
Revista Calundu - vol.3, n.1, jan-jun 2019

direitos a serem garantidos a esses povos, a fim de salvaguardar os seus específicos modos de ser e pertencer ao mundo. É necessário compreender o histórico de violência que essas religiões viveram e que repercute em "novas roupagens", para que seja de fato garantido o direito humano fundamental à liberdade religiosa.

O julgamento do abate religioso trouxe à tona todo esse contexto e por mais absurdo que seja um tribunal ter que dizer se uma prática religiosa é ou não constitucional, essa decisão é um marco por reconhecer como, ainda, as religiões afrobrasileiras sofrem preconceito e discriminação e quanto, ainda, temos que lutar e caminhar para que o direito à liberdade religiosa seja vivenciado plenamente por essas religiões. E, todo esse debate só foi possível pela mobilização e união do povo de santo que luta cotidianamente para a proteção e manutenção dos seus territórios tradicionais e das suas práticas ancestrais. Acredito que essa decisão pode contribuir para a construção positiva da identidade dos povos tradicionais de matriz africana, como forma de intervenção contra o racismo.

\section{Referências bibliográficas}

BASILIO DE OLIVEIRA, Ariadne Moreira. Religiões Afro-Brasileiras e o Racismo: contribuição para a categorização do racismo religioso. 2017, 102f. Dissertação de Mestrado em Direitos Humanos - Universidade de Brasília. Brasília, 2017.

FLOR DO NASCIMENTO, Wanderson. O Fenômeno do Racismo Religioso: desafios para os Povos Tradicionais de Matrizes Africanas. Revista Eixo. Brasília, v. 6, n.2 (especial), novembro, 2017.

MINISTÉRIO DAS MULHERES, DA IGUALDADE RACIAL, DA JUVENTUDE E DOS DIREITOS HUMANOS - MDH. Relatório sobre a intolerância e a violência religiosa no Brasil (2011-2015): resultados preliminares. FONSECA, Alexandre Brasil. ADAD, Clara Jane Costa (org.). Brasília: Secretaria Especial de Direitos Humanos, 2016.

MINISTÉRIO DAS MULHERES, DA IGUALDADE RACIAL, DA JUVENTUDE E DOS DIREITOS HUMANOS - MDH. Gráfico que apresenta os casos em que as 
Revista Calundu - vol.3, n.1, jan-jun 2019

vítimas são pertencentes às religiões de matriz africana. Disponível em: http://www.mdh.gov.br/informacao-ao-cidadao/disk-100. Acesso em 29/03/2019.

BRASIL. Supremo Tribunal Federal, Recurso Extraordinário n. 494.60 (RE), 2019.

Recebido em: 05/05/2019

Aceito em: 13/05/2019 